\title{
Andrea Hanebuth*
}

\section{Success factors of virtual research teams - Does distance still matter? ${ }^{* *}$}

Purpose of the exploratory study in this paper is to provide a first test of the transferability of success factors known from virtual teams to an innovative virtual research team. Investigating a real R\&D cooperation with two virtual (regional \& national) and one local research groups permits a comparative analysis of the influence of geographical distance. Though success factors seem to be somehow transferable, the geographical distance is still an influencing factor on the perception in virtual research teams. Based on results of this case study and 18 interviews, a ranking of success factors is provided which may help research managers in understanding where to place emphasis situationally on in order to successfully manage a virtual research team.

Key words: research collaboration, virtual teams, manage innovation (JEL: L33, M19, M54)

* Andrea Hanebuth, Technical University Bergakademie Freiberg, Chair of Management, Leadership and Human Resources, German Centre for Energy Resources.

E-mail: andrea.hanebuth@der.tu-freiberg.de.

** Article received: July 31, 2014

Revised version accepted after double blind review: May 12, 2015. 


\section{Virtual teams and relevant success factors}

Increasing stress of competition on the global market, increasing complexity in products and processes, escalating costs in research and development (R\&D), death of resources, altogether supported by new designs and development in the information and communication technologies (ICT) have been movements in the last two decades (Davidow \& Malone, 1992; Snow, Miles, \& Coleman, JR., 1992; Weisenfeld, Fisscher, Pearson, \& Brockhoff, 2001; Picot, Reichwald, \& Wigand, 2003; Gassmann, 2006). With these streams, the concept of the virtual organization realized through virtual teams evolved and "virtual organization" became a buzzword in the 1990s (KasperFuehrer \& Ashkanasy, 2003) in organizational research.

The research on virtual organization started with the book by Davidow and Malone (1992) and the article by Byrne, Brand and Port (1993) about new forms of organizations and cooperation which will evolve based on the markets' needs, regardless of existing organizational boundaries. Lipnack and Stamps (1997) picked up on the idea and provided one of the first books dealing with aspects on the virtual team level. This new perspective on the team level added the influence factors which focused on the people working in this virtual environment. According to Powell, Piccoli and Ives (2004a), virtual teams are defined as groups of geographically, organizationally and/or time dispersed workers brought together by information and telecommunication technologies to accomplish one or more organizational tasks. They can be ongoing or assembled on an "as needed basis" and cooperate on deliverables or fulfillment of customer needs. Virtual teams work task-oriented, rely - sometimes exclusively - on IT-based communication, exist as a flexible composition and cross traditional organizational boundaries (Powell, Piccoli, \& Ives, 2004a). They reduce travel and time costs, enable recruiting talented people, engender creativity and originality among team members, allow building diverse teams and assist in setting up diverse teams which are open to disadvantaged individuals and groups and reduces discrimination (Bergiel, Bergiel, \& Balsmeier, 2008). Virtual teams seem to answer the challenges of effectively organizing cooperation today. Hence, research studies focused on the successful set up and management of these virtual teams. Literature provides a variety of success factors for this field. The following Table 1 summarizes some of the most cited (according to Google Scholar) and relevant articles on success factors in the virtual team context.

Despite the variety of structuring and presenting success factors of virtual teams, there are several groups of success factors that can be identified. These are (1) Leadership aspects and management, (2) processes, standards and structure, (3) communication, technology and experience in working in the virtual environment, (4) organizational culture \& trust, and (5) human resource management and training. Some concepts do not cover all of the identified success factor groups (see Johnson, Heimann, \& O’Neill, 2000; Kirkman, Rosen, Gibson, Tesluk, \& McPherson, 2002; Hertel, Geister, \& Konradt, 2005). Comparing the remaining concepts, there are several reasons for choosing Duarte and Snyder (2006) as referring concept for this case study. (1) The concept includes the members' assessment of leaders' competencies, of own competencies and of the working environment. (2) Duarte and Snyder (2006) provide 
Table 1: Overview of most cited success factors (according to Google Scholar)

\begin{tabular}{|c|c|c|c|c|c|c|c|c|}
\hline 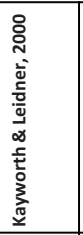 & 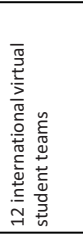 & 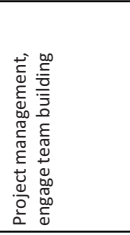 & 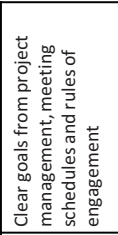 & 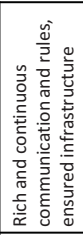 & 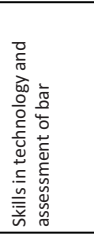 & 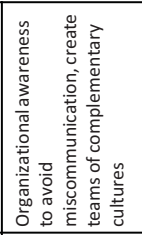 & 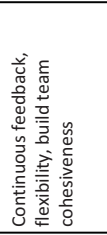 & 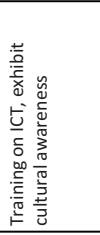 \\
\hline 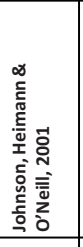 & 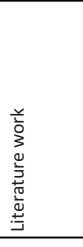 & & 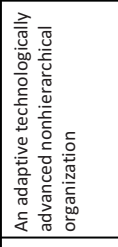 & 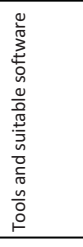 & 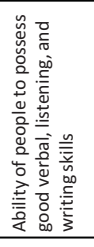 & 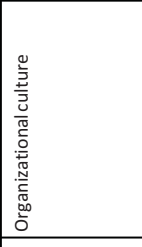 & 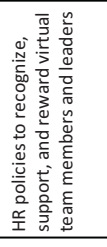 & 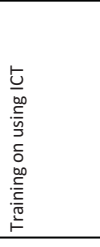 \\
\hline 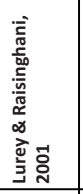 & 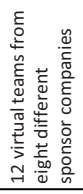 & 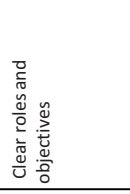 & 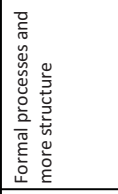 & 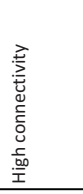 & 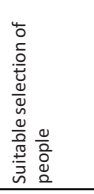 & 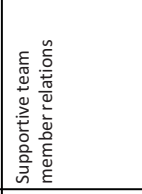 & 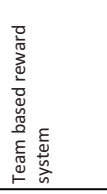 & \\
\hline 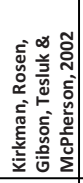 & 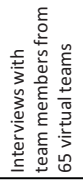 & 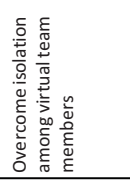 & & & 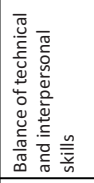 & 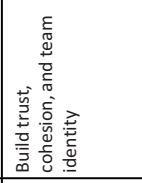 & 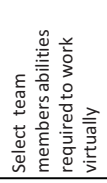 & \\
\hline 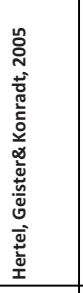 & 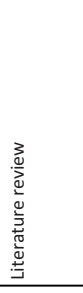 & 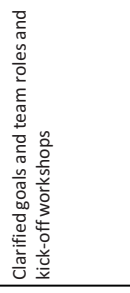 & 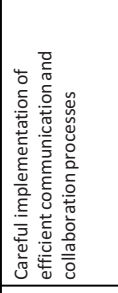 & & & 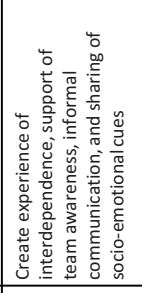 & 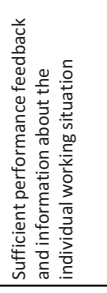 & 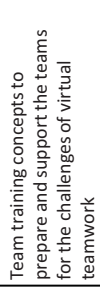 \\
\hline 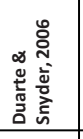 & 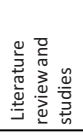 & 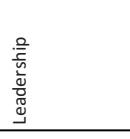 & 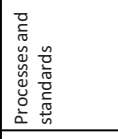 & $\underline{\underline{t}}$ & 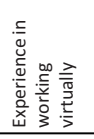 & 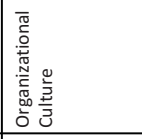 & 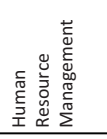 & 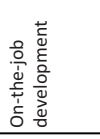 \\
\hline 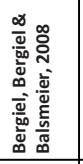 & 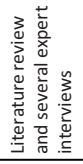 & 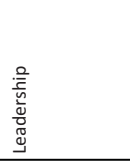 & 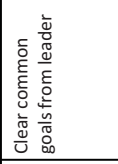 & 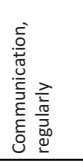 & 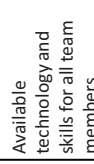 & 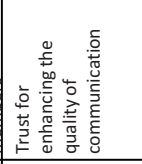 & 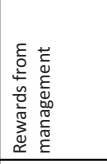 & \\
\hline 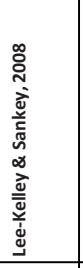 & & 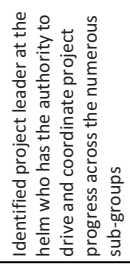 & 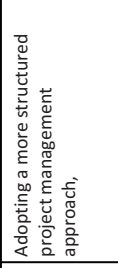 & 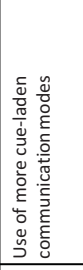 & 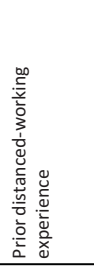 & 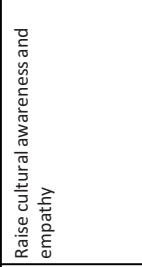 & 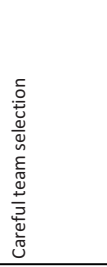 & 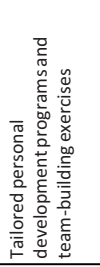 \\
\hline 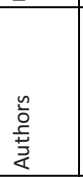 & 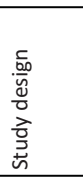 & 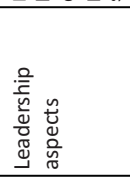 & 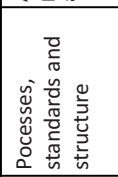 & \multicolumn{2}{|c|}{ 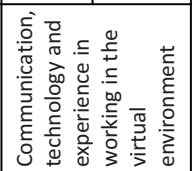 } & 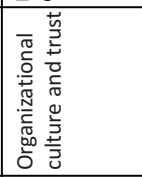 & \multicolumn{2}{|l|}{ 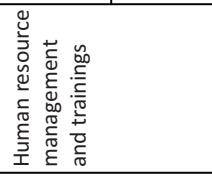 } \\
\hline
\end{tabular}


a clearly structured set of questions which have been tested and further elaborated and refer as base for developing a structured study. (3) Duarte and Snyder (2006) developed their set of success factors from their experience as consultants and experts in bottom-line and results-oriented organizations in North America. This third reason includes a potential bias which needs to be considered during analysis. (4) The set of success factors from Duarte and Snyder have been developed based on longitudinal studies. Consequently, these points do not only cover aspects which appear at one phase during the life cycle of virtual teams. Duarte and Snyder (2006) consider the success factors as bundle of factors for preparing people and organizations for interacting in virtual teams. Even though there is no need to have all of the factors in place at once, a plan needs to assure that all factors are systematically addressed (Duarte \& Snyder, 2006). For these reasons and due to the fact that the book is more often cited than the other concepts, the set of Duarte and Snyder which is presented in the following paragraph will be used for the following case study.

These relevant seven factors are: Communication and technology, as it is essential to provide the suitable communication technologies and have them working on all systems and personal computers, and to have the team members skilled or trained, too. The team leader should be willing to model the use of the advanced forms of electronic cooperation technology. The second success factor 'Processes and standards' covers the development and the implementation of standard team processes in order to reduce the startup time. The processes include "hard" areas, such as project planning, documentation and documentation sharing, common software but also "soft" areas, such as the establishment of norms, conflict resolution procedures and communication routines. The third success factor is the organizational culture which includes norms regarding shared leadership and cross-boundary collaboration, value creation that supports respectful intercultural cooperation, constructive criticism and information sharing - in short: how the virtual team members work together trustfully. The fourth success factor considers human resource management which should support through establishing the suitable policies for working virtually. This includes career development systems (provide team members quite the same career development opportunities as the members of traditional teams), rewards for cross-boundary work and results (systems that stimulate and reward virtual teamwork and translate performance measures of face-to-face environment to ones that work in a virtual environment) and resources and support for working virtually (in addition to equal and immediate access to systems and technology, training and support, establishing a "virtual SWAT team" might be an option). On-the-job development and qualification as fifth success factor summarizes more than formal training in using technology which is vital for success. It includes longitudinal and constant (online) training, too. The leaders have to make sure that the members have access to technical support and systems for sharing knowledge and lessons learned across functions, projects, and organizations. Leadership as sixth success factor covers four behaviors that support the virtual team success. These behaviors are communicating (e.g. communicate the necessity of the team, the respect of virtual teamwork, the value of diversity and of leveraging skills), establishing expectations (e.g. set clear procedures and goals, expectation of stakeholders, factor in startup costs and times), allocating resources (e.g. allocate time 
and money for training of members and for traveling) and modeling behaviors (e.g. align cross-functional and regional goals, cooperate on the management team level across geographic and cultural boundaries, show flexibility). The last success factor considers experiences in working in the virtual environment on both levels. The team leaders have to establish trust in an environment with barely face-to-face contact or feedback and have to ensure that the previous mentioned success factors are implemented. The team members have to develop their own competencies in networking (across functional, hierarchical and organizational boundaries) and in handling this instable environment which includes e.g. managing one's career and time, project management techniques, using collaboration technologies effectively, and a high level of interpersonal awareness.

\section{Virtual teams and their relevance in the research context}

Research on virtual organizations and virtual teams is still up-to-date (Hanebuth, 2015) and research in the virtual team context so far mainly focused on new products, business development and customer service teams (Powell, Piccoli, \& Ives, 2004b). It is about to overcome the existing boundaries in order to make active use of competences and knowledge that exist outside the company and that lie to waste or still offer potential? This was and still is the driving force. But opening up the own boundaries and involving partners also implies changes for the partners. Research institutes and universities became partners and the concepts also found their way into their daily routine. The concepts of open innovation (see Chesbrough, Vanhaverbeke, \& West, 2006) and Triple Helix (see Etzkowitz, 2008) are just two concepts which evolved through these changes in organizing cooperation and new forms of communication. Virtual R\&D teams cooperate broadly on an "innovation-based relationship that involves, at least partly, a significant effort in research and development (R\&D)" (Hagedoorn, Link, \& Vonortas, 2000). Many R\&D organizations use virtual teams for several activities as the required specialized expertise to solve new problems or engage in complex discovery processes usually is not located in a single organization or place (Duarte \& Snyder, 2006).

Research in universities and research organizations often happens in collaboration and those collaborations are mainly realized by virtual teams. The program "Entrepreneurial Regions - The BMBF Innovation Initiative for the New German Länder" is just one initiative for virtual national research cooperation (see BMBF, 2010). One example from this program will be used for the case study following afterwards. This paper aims at testing the the success factors of virtual teams in a company's environment - known from literature - in a virtual R\&D team outside of companies. Lastly, some differences that exist due to the geographical distance between the virtual team members will be included in the study, too. Research has shown that physical distance and dispersion between team members led to a lower likelihood to develop relational ties and lower likelihood of communication (Axtell, Fleck, \& Turner, 2004). However, the options for communication changed in recent years and personal habits of using webinars, video-conferences and web-based forms of communication may have developed. Consequently, the geographic aspect will be included in the study presented. 
As presented before, research on virtual $\mathrm{R} \& \mathrm{D}$ teams mainly dealt with aspects from a company's point of view (see Gassmann \& von Zedtwitz, 2003; Kratzer, Leenders, \& van Engelen, 2006) and, especially in the public sector, research on virtual teams is somehow meager. Innovation is a random process and R\&D performance is hard to measure (Thamhain, 2003). This in combination with the non-linear and high risk environment constitute the special context of virtual R\&D teams. Following the contingency approach, this paper addresses the following research question:

Are virtual team success factors by Duarte and Snyder (2006) transferable to the innovation context in the public sector and are some of the aspects more relevant in the innovation context?

The paper is structured as follows: After briefly explaining the adopted choice of case study and research approach, results will be presented and discussed. The paper will close with limitations, options for future research and managerial contributions for the R\&D management.

\section{Methodology}

Interviews with 18 researchers were used in order to analyse whether the critical success factors for virtual teams are also critical success factors for virtual teams working and cooperating in research projects. Based on the actual situation of the project, all the factors have been discussed with the interviewees in order to elaborate whether these success factors make sense, are applicable and relevant from the participant's point of view. Lastly, the goal of this pilot study is to find out whether the geographic distance still plays a role and causes differences in the perception and estimation of the interviewees as already shown in earlier studies (e.g. Kraut, Egido, \& Galegher, 1988).

\section{Survey}

This exploratory study used a structured survey as frame for semi-structured interviews. The interviews were separated in seven sections based on seven elaborated success factors of virtual teams known from literature (see Duarte \& Snyder, 2006):

- Information and communication technology (ICT)

- Processes and standards

- Organizational culture

- Human resource management

- On-the-job development and qualification

- Leadership

- Competence and experience in working in the virtual environment.

The sections were operationalized according to the checklists provided by Duarte and Snyder (2006), translated into German language and slightly adapted to the project context. The questionnaire provided by Duarte and Snyder (2006) contained four questions for each success factor. The set was enriched through questions which asked for the own routine and added a second perspective. In this way, respondents answered on their perception of the team and on their own practice. In addition to 
that, the set of questions on organizational culture was enlarged through questions which targeted the dominating commitment of the respondents (commitment to team vs. organization or institute). This commitment aspect is highlighted in research on virtual teams in the technology context (see Weisenfeld et al., 2001). The number of aspects regarding leadership mounts due to the fact that some of the presented issues in the original set needed to be separated as they combined several aspects in one question. Through this, the set of questions included 44 statements at the end. Finally, a questions on the satisfaction within the research team concluded the interview.

First, the interviewees had to answer questions on each section and quantify their answers (range 1 to $4 ; 4=$ totally agree, $3=$ rather agree, $2=$ rather disagree, $1=$ totally disagree). Second, they also had the possibility to comment on their answers. Thus, profound set of qualitative data was gained. Each section was rounded off with a summing up question for their valuation of the section ( $1=$ not important, $3=$ ok, 5 $=$ very important). The interviews were conducted at half-time of a five year project and lasted approximately 45 minutes. The answers were documented and summarized.

\section{Sample}

18 Researchers from eight different institutes and five different universities and semiprivate research organizations cooperating in one complex research project in Germany participated in the study. More than ten similar research projects have been funded from government in the same innovation oriented initiative. All the interviewees have different line managers respectively professors whom they are answerable to and who are somehow involved in the project, too. These researchers cover a wide range of different disciplines (e.g. material science, chemistry, process engineering, business administration or psychology) and, hence, the group is very heterogeneous concerning the point of view on the topic "virtual teams". In this context, the terms "team" and "group" are used as synonyms. The project leaders are also supervisors of some group members. Half the interviewees of the whole project group are part of other institutes or organizations, thus have different supervisors. The project coordinator is responsible for keeping track of the project, reporting and marketing the project but is no direct supervisor of any team member. The organizational structure looks as follows (Figure 1).

Figure 1: Structure within the research project

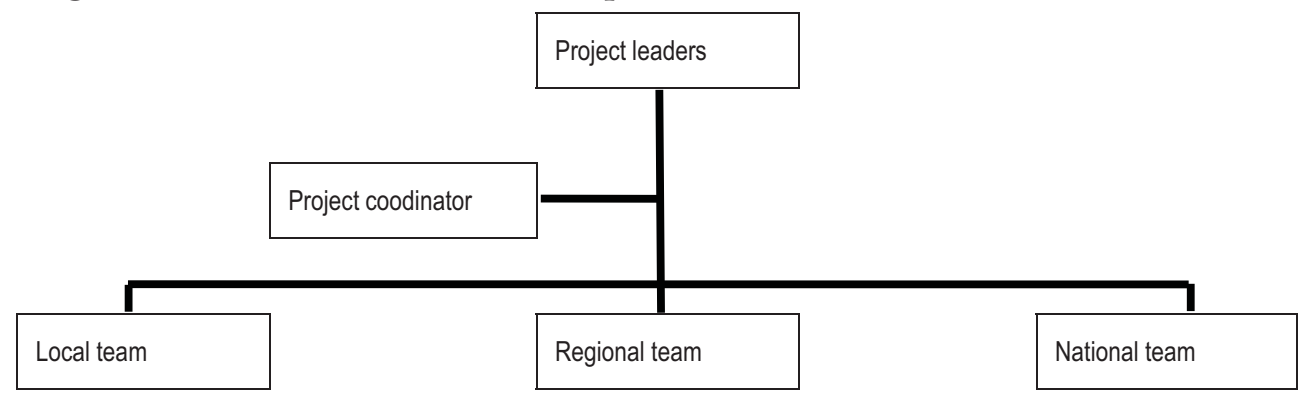

The thematic groups of the project can be structured in three teams with different geographic distances. The local group which is located in one building on the same floor 
focused on business research issues. The regional group located within a distance of 100 kilometers focused on analytic research and the national group with a maximum distance of more than 600 kilometers concentrated on material research. The following Table 2 provides an overview of the groups' structure and geographical distance. The maximum distance in the regional group is 96 kilometers; the maximum distance in the national group is 630 kilometers.

Table 2: Structure and distance in the groups

\begin{tabular}{l|l}
\hline \multicolumn{1}{c|}{ No. of members } & \multicolumn{1}{|c}{ Distance to headquarter (=location of project coordinator) } \\
\hline 3 & 10 meters (same floor) headquarter \\
\hline 3 & \multicolumn{1}{|c}{ Regional group } \\
\hline 1 & 4 meters (same office) headquarter \\
\hline 1 & 20 meters (same floor) headquarter \\
\hline 1 & 200 meters (same area, different building) \\
\hline 2 & 3,1 kilometers (same city) \\
\hline 1 & 3,5 kilometers (same city) \\
\hline 1 & 96 kilometers (same region, different city) \\
\hline 1 & \\
\hline 1 & headquarter \\
\hline
\end{tabular}

Referring to the definition of a virtual team given in the beginning, regional and national groups are geographically and organizationally dispersed, brought together via ICT to accomplish their research task and, hence, fulfill the criteria of virtual teams. The local group will serve as a base to refer to but represents no virtual team.

Figure 2 illustrates the density of directed communication. The thickness of arrows represents the frequency of communication among the team members. Participants were were asked to provide information with whom they communicate daily, weekly, monthly, or sporadically. The thickest arrows represent daily communication. 
Figure 2: Intensity of communication of the different teams

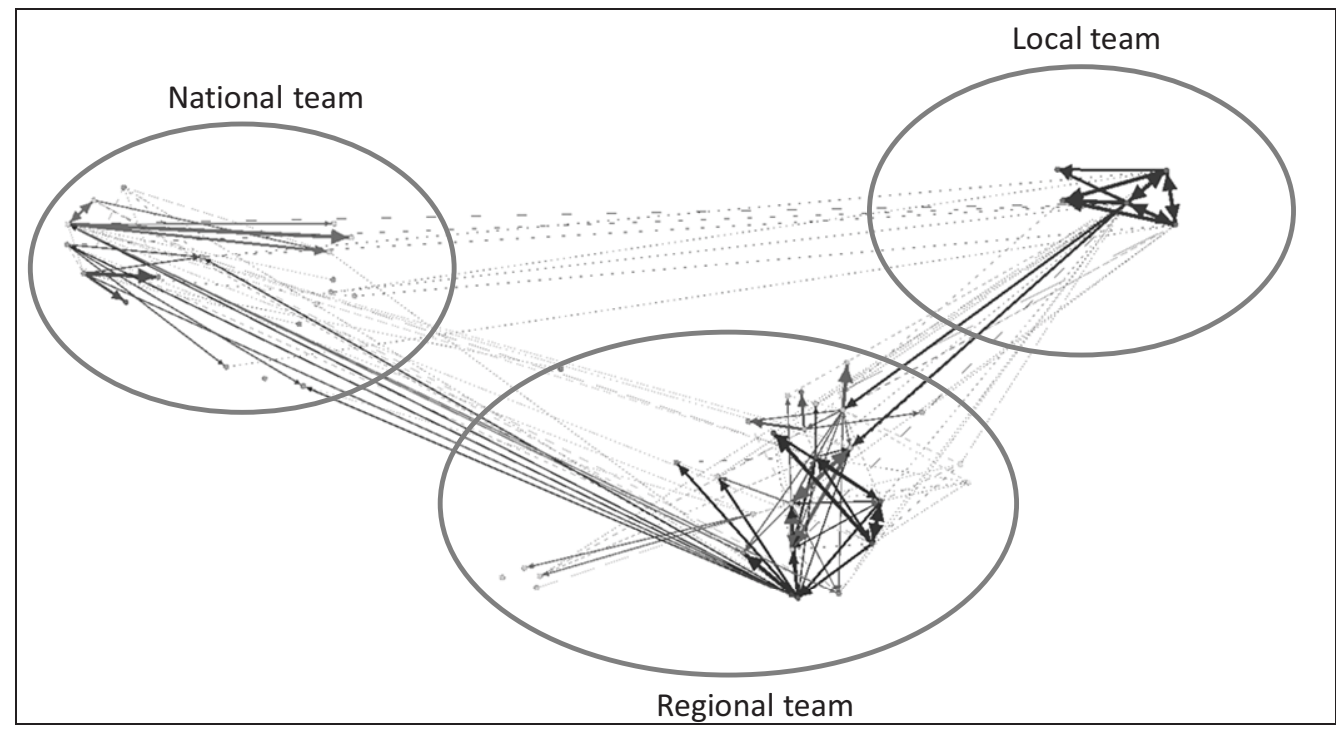

\section{Results}

These results provide profound insights into a real virtual research cooperation differentiating between three groups (local, regional, national) which are all part of one research project which is still running.

The results include the actual valuation and applicability of the success factors for virtual teams known from literature. The following paragraphs summarize the results of the interviews. For detailed data see Table 3 in the appendix.

\section{Information and communication technology (ICT)}

Development in the ICTs prepared the way for this new form of cooperation. Nevertheless it cannot be taken for granted to find all people equipped and trained in a suitable way. In order to understand the valuation of the different groups it is also necessary to take the situation into account in which the valuation takes place.

The communication and technology situation (equipment, access and training) in all three groups was described as quite satisfactory for all the researchers. The local group - though located on the same floor - also uses a chat room in order to leave notes without disturbing each other from the actual work. Researchers in the regional group see the equipment as reasonable and remark the efficient use of ICT as more important than communication standards. It seems that there are less communication standards the bigger the distances between the research groups are. On the other hand, the national team members feel better skilled in using ICT than the regional and the local team. Altogether the aspect of being equipped and trained with the actual ICT is highlighted to be important and crucial for all the research groups regardless of the distance over which they are cooperating. 


\section{Processes and standards}

Standardized project processes do apparently exist and are used in all the groups. Regular meetings and group jour fixes are held and guarantee some routine and an efficient workflow. Team members who joined the project after the very beginning, though, mentioned that sometimes it is not clear which standards do exist and that they are not actively looking for existing standards if it is not recommended to them. Nevertheless, they do have access to all the information they need in order to fulfill their task. Coming to informal standards it is remarkable that, according to members' perception, informal standards are obviously shrinking with the growing distance between the team members. All interviewees confirm that the processes over all teams are flexible in the way that they get adjusted if necessary. The overall importance of the existence and suitability is highly appreciated by the participants. Participants state that it is "necessary to have these standards" even though "they cost a lot of time".

\section{Organizational culture}

The organization culture within the close research team and within the home institute where they are located is generally described as very trustful by the members. This kind of relationship is described as the base for successful research by several members from different teams. One respondent summarized that "without a trustful working atmosphere, communication and knowledge transfer would be impossible." Another aspect mentioned in one of the interviews was the good atmosphere to be the determining factor for job choice. This importance highlighted through two statements seems to get confirmed by the indication of spending time with colleagues outside business hours. Based on the assigned scores in this study, the relation within the close group is described as more trustful than within the whole project team. Some members of the regional group mentioned to be under the impression that "everybody keeps on his own thing and doesn't care about the others". Some members of the national team said they see each other also as competitors even within the national group. Concerning the appreciation among the researchers, data of this project shows indicators for a shrinking valuation going along with growing distance between the partners. Coming to the questions about affiliation, lots of interviewees had problems to answer the questions and first had to think about an appropriate answer. It seems that the closer the researchers are located to headquarter, the more they identify themselves with the project. Vice versa, the bigger the geographical distance, the more they seem to identify themselves with their affiliation where they are located. One interviewee summarized that "there is some 'national pride' for the institute I am from and the whole project is just a loose alliance." There was only one interviewee in the regional group who mentioned to feel belonging more to the project than to the institute. All the interviewees mentioned to feel supported by their general work environment. The overall importance of a positive, trustful and supportive organizational culture is very important to all the interviewees. And it was named a lot more important than the ICT aspect and the existing standard and process aspect.

\section{Human resource management (HRM)}

Concerning the HRM aspects the answers have been very heterogeneous. In the investigated overall project there is obviously no reward system existing which rewards 
the cooperation over geographic distances. If it comes to personal rewards the picture has to be explained. Most of the interviewees answered the question of being rewarded for research success referring to their boss respectively professor. The members of the local and the national group feel quite rewarded for their research successes whereas the regional group feels a lot less rewarded. Coming to the rewards for project success, the interviewees referred to the project coordinator. Now the answers of the members were positive throughout. The local group indicated a better score to be rewarded for the project successes. When it comes to rather unconventional and flexible work arrangements and the valuation of the project leadership the local group feels supported, whereas the regional group doesn't feel supported. The interviewees in the national group often could not give an answer as they mentioned that they just don't know about the position of the project leaders. Additionally, as the project leaders have no influence on their work arrangement (they are employed by a different organization or institute) the position of the project leaders does not have any consequences. The last two questions focused on the characteristics of the interviewees stepping forward for their interests and being proactive. As all of the participants seem to see themselves as proactive and willing to participate in important decisions, the circumstances in the project are in some way satisfactory to them. This might also be based on the fact that most of the interviewed researchers see research success as stepping forward in their career and a positive personal effect. For this reason positive feedback and receiving approval are perceived as motivating factor but it is not expected and the researchers actually see no need for a reward system. The HRM aspects have an overall valuation but play a minor role from employees' point of view. This does not include that members have no interest on these topics but they seem to focus on other aspects.

\section{On-the-job development and qualification}

The qualification aspect also seems to play a minor role for the researchers. Two interviewees of the whole sample named interesting trainings which they have been provided with by the project. Some participants even mentioned that they would like to have more possibilities for on-the-job development both to further qualify themselves and also to get an overall understanding of the research outside but close to their own research focus. Local group members demanded more training offered through the project whereas members of the regional group took a more neutral position. Some members of the national group mentioned that it is even marginal in its importance and that there is not enough time left over for training. The answers on trainings offered by the employer have been also quite heterogeneous (see SD in Table 3 in the appendix). In this case study, all the organizations or institutions offer overall trainings. Obviously the offer of trainings for intercultural cooperation in this sample is bigger than the offer of training supporting the cooperation over geographical distances. Researchers in this study perceive on-the-job development and training as important and necessary but on the other hand - as daily work for researchers is research - they feel to train themselves during their work. This and the lack of time might be the reasons why the emphasis on these aspects plays a minor role in the project from the interviewees' point of view. 


\section{Leadership}

The leadership aspect evolved to a central part of the interviews. It is remarkable that the local group feels less supported by the project coordinator than the regional or the national group. Answers included statements as "it is not my first contact person" and "I rather get the information from somebody else before asking the coordinator." Another comment was: "Why should I make a suggestion for improvement? If I tell my idea, I have to do the additional job on top and I already have not enough time for my own work. So why should I share my ideas just to get more work?” On the other hand, most of the interviewees from the regional and national group mentioned that they had never tested whether the coordinator would support them. Before contacting the project coordinator, some members from the regional and national group mentioned to ask their on-site colleagues and team leaders. Again, the development and support of working across organizational boundaries and using new communication technologies is rather negated in the local group but strongly confirmed by interviewees from the regional and national group. The overall rating of the project coordinator is consistently positive. There was only one person in the local group rather negating the support and cooperativeness of the coordinator. Furthermore members of the local group seem less satisfied with the familiarity and use of ICT through the project coordinator. The regional and even more the national group were quite satisfied with ICT usage. The questions on valuating the leader aimed at making the interviewees think about the current situation and related importance of the coordinating person for the success of the team. The answers of all the interviews had the same quintessence. From the members' perspective, the leader in a virtual research project plays a central role for the success of the project for "giving impetus and keep the ship on course". Interviewees stated that it is crucial that the coordinator is open and easy to approach. "Not all the people have the same drive and some need some driving and leading force," mentioned one of the researchers in order to highlight the personal expectation at a coordinator. Some interviewees see the coordinator as communication facilitator to the leading level. Researchers in this study consider it as necessary that the coordinator is able to motivate people and keep them on track, "especially in large groups". Regarding the overall assessment of suitable leadership as success factor, this factor scored highest compared to the other success factors.

\section{Competence and experience}

The aspect of competence and experience in the virtual environment asked about know-how in working across organizational boundaries and geographic distances while using mainly ICT for communication. Regarding the opinions of the experience of the project coordinator, the answers differed between the local and the regional and national group. The regional and national groups perceive the project coordinator as higher experienced in working in the virtual environment and across organizational boundaries and geographic distances than the members of the local group. The two groups assess the experience of the project coordinator quite positive both in working across distances and organizational boundaries. The valuation of their own experience in working in the virtual environment turns out to show a different picture and the own experience was ranked lower. The members of the local and the national group 
feel quite experienced in working in the virtual environment. The regional group, though, feels quite experienced in working in the virtual environment whereas the single aspects of being experienced in working across organizational boundaries and distances are estimated lower. This kind of contradiction could be explained through the attempt to answer the question related to the score they gave for the project coordinator. Most of the interviewees mentioned to have problems with these questions as they do not know about the experience of the coordinator and that most of them had no reference to compare the experience with. Some mentioned that probably the coordinator is gaining the experience by running the project, so to speak learning by doing. Others mentioned that the coordinator is somehow doing it, so he "must be capable" and that they do not see a reason for him not being experienced. It seems that the team members make assumptions about the capabilities of the coordinator. The importance of this competence and experience for the project members and the coordinator are estimated to be relevant not only for these kinds of projects but in general. Members of the regional group answered that there is "nothing special about it" but also that some experience has to be shown and that especially the coordinating person "should have a clue". Interviewees of the national group highlighted that it is even crucial to be experienced especially for the coordinator in order to build closer connections within the project and to take care of the merging of the partners. Thus, the overall valuation of this success factor for virtual teams is quite high.

\section{Discussion}

\section{Transferability of success factors}

According to the presented data, all success factors are assessed as relevant from the virtual team members' perspective. The investigation also shows that the success factors of virtual teams show some kind of ranking in combination with the situation presented in this case. The interviewees ranked the seven success factors as 'ok = 3', 'important $=4$ ' or 'very important $=5$ ' (see Figure 3). Scores as 'less important $=2$ ' or 'not important at all $=1$ ' were not selected from any of the respondents.

Nevertheless, the results of this pilot study recommend some kind of ranking of these success factors. Human resource management aspects together with training onthe-job and development seem to play a minor role compared to other success factors in the presented context. It seems that these researchers - perhaps due to their permanent access to "new" knowledge - do not actively look for training on soft skills. In fact, if anything, they are interested in technical training, in order to improve their research skills. Feedback and human resource management is a motivating factor but rather in the way that people want to be apprehended at all. Standards and clear processes play a role for researchers, too, but in their opinion it is important to keep their degree manageable and intuitive. Thus, the processes and standards seem to play a secondary role. Furthermore, the suitable equipment of ICT is a necessity all the researchers seem to be aware of. Obviously, as the big part of researchers in this study feel skilled and well equipped, their emphasis lies on other factors. Cultural aspects in their work environment are more important than e.g. HRM aspects. Researchers perceived it as crucial to work in a trustful and amicable environment. Based on the results, they appreciate mutual support and stimulating flair which respects different cul- 
tures. Regarding the experience in working in a virtual environment, this success factor also plays a very important role but at the same time researchers regard it as something of special importance to the project coordinator. Members perceive it as crucial that the project coordinator is somewhat skilled and experienced as he/she is the unifying person. This leads straight to the last highly important factor: the coordinating person, besides being experienced, needs to be a bridge builder. Interviewed researchers consider openness, support, and serving as glue in this loose composition, holding members together by their task, as central for the success of a virtual team.

Figure 3: Mean rating of the success factors by the project members (graphical illustration at $95 \%$ confidence interval $(n=18)$ )

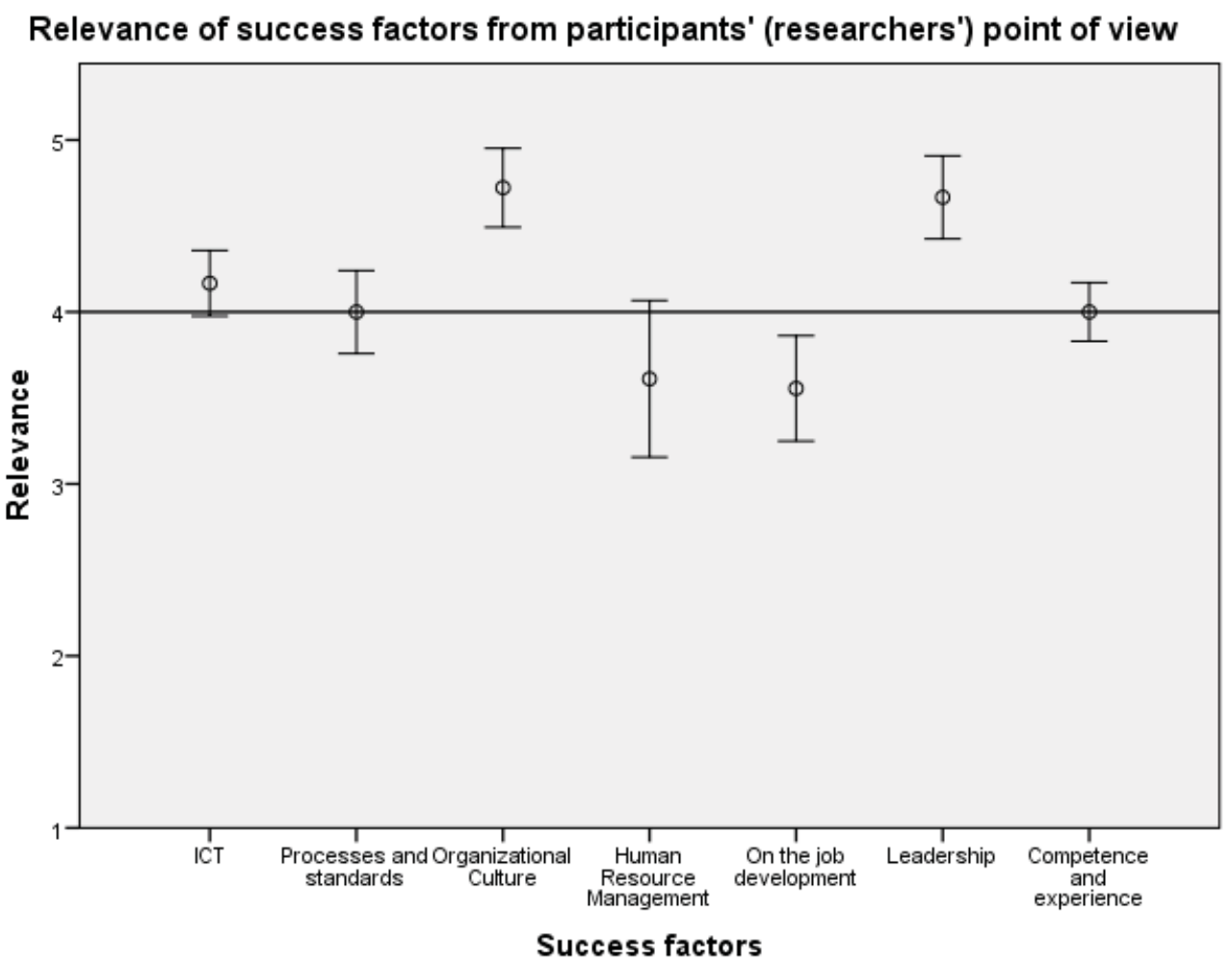

This ranking which provides a snapshot during a five-year research project can be used for focusing on some points which were less clear in the beginning of this study. Given the presented situation with satisfied team members (all enjoy being part of the team, see Table 3), established structures, processes, responsibilities, human resource systems and equipment, researchers seem to emphasize on factors which concentrate on human interaction. In the presented case, the highly ranked 'soft factors' (which depend on the people who practice them) of working in a trustful and helpful (virtual) environment and of suitable professional leadership are considered as most essential for success. These findings support other studies, too, which already focused on e.g. 
building a knowledge-sharing culture (Zakaria, Amelinckx, \& Wilemon, 2004) and leadership in virtual teams (e.g. Bell \& Kozlowski, 2002; Kayworth \& Leidner, 2002).

\section{Influence of geographical distance}

Coming to the ICT success factor, the different groups do not show big differences in their answers. Thus, based on this study, this success factor seems to be less influenced by the geographical closeness. It is different regarding the process and standards aspect. Results of our study suppose that the shrinking use of informal standards within a whole project attends to the growing geographical distance. This could be caused by the fact that, within the national group, a lot less researchers rely on their colleagues to fulfill their work as mentioned in another question. Same applies for the identification with the whole project respectively the dispersed group which also goes along with the growing geographical distance. This might be rooted in the fact that the processes and standards are less present in their daily work sitting with another institute/organization. Our data shows that the members of the local team feel more appreciated by their team colleagues than the regional team and those still more than the national team. Furthermore, the local team feels more rewarded in the project than the regional and the national team. The reason for this valuation could lie in the fact that close located people communicate more often and the project coordinator faces more situations to reward the people. The training and development aspect is higher appreciated and demanded the closer the teams are located. This could be up to the higher identification with the project and the inspiration through the close team members. Concerning the leadership aspect, it is remarkable that the local group rated the situation considerably worse than the other groups. This could either be rooted in the fact that a local group expects a different leadership than a virtual group. Or, it could be explained with higher identification in the project through the local group or the background of the local group which is doing business research and might have different expectations. This also can be found in the aspect of experience in a virtual environment. The regional and the national group see the coordinator somehow higher experienced than the local group. Thus, slight differences on the operationalized level of success factors can be observed but due to the small sample size, not general trends can be elaborated. However, the geographic distance seemed to have few influence on the valuation of the success factors as the interview groups ranked the factors in a similar way. Analyzing the concrete circumstances of the teams, slight differences regarding the perception, characteristics and management requirements of virtual teams can be observed compared to co-located teams.

\section{Limitations and future research}

Due to the exploratory character of this paper and the small sample size, it is necessary to mention some limitations of the study. One limitation is the sampling method: the selection of one single research project and, thus, participating virtual team members was not random. However, this random sampling was not an option as purposeful selection of participants was essential. People who took part in the study were the only ones who were knowledgeable and hence capable to give the essential feedback in this context. This comparison of three research teams precludes vast generalization; however, several first conclusions are still warranted. Another limitation is the fact 
that the perspective of the project leader is missing. Further studies should include both perspectives of necessities for success in a virtual R\&D team. Additionally, including success factors from the innovation management perspective e.g. the open innovation research would add an interesting angle in this context. Lastly, the pilot study paper focused exclusively on members from national public organizations. An insightful aspect would be to enlarge the analysis to a large international scale and to include partners from different forms of organization (e.g. Triple Helix (Etzkowitz, 2008)). The study also proved that the geographical closeness still plays an important role and that it would be worth further investigating how to act as a research manager according to the situation on hand.

\section{Conclusion}

This pilot case study aimed at analyzing whether the set of success factors by Duarte and Snyder (2006) from the companies' context is transferable to a real virtual research team. According to the results, success factors seem to be transferable but there is evidence for a need for future research in order to understand why some of the success factors seem to be more important in the innovation context than others, e.g. leadership, organizational culture and experience in working in a virtual environment. Additionally, the study of today's research project showed that it still seems to be necessary to include the geographical distance as an influencing factor when it comes to managing teams and groups which are geographically dispersed even though new and enriched forms of communication have been developed in the last years. Lots of single aspects such as identification with the project and a trustful amicable organizational culture, standards \& processes, experience in working virtually, and especially the leadership aspects are rated slightly heterogeneously with growing geographical distance between the team members. This demand for a situational approach needs to be considered by project and team management. According to the data, today's researchers seem to be aware of the importance and wish for suitable ICT, clear goals and objectives, trustful organizational culture and a reliable and experienced leader who is easy to approach. Research managers in virtual teams in the public sector should put emphasis on these aspects in order to provide a suitable environment, motivate the talented people and consequently successfully manage a virtual research team.

\section{References}

Axtell, C. M., Fleck, S. J., \& Turner, N. (2004). Virtual teams: Collaborating across distance. International review of industrial and organizational psychology, 19, 205-248.

Bell, B. S., \& Kozlowski, S. W. (2002). A typology of virtual teams implications for effective leadership. Group \& Organization Management, 27(1), 14-49.

Bergiel, B. J., Bergiel, E. B., \& Balsmeier, P. W. (2008). Nature of virtual teams: a summary of their advantages and disadvantages. Management Research News, 31(2), 99-110.

BMBF. Spitzenforschung und Innovation in den Neuen Ländern. http://www.unternehmen-region.de/de/3899.php, 6 Dec 2010, 22 Apr 2012.

Byrne, J., Brand, R., \& Port, O. (1993). The virtual corporation. Business Week, 8(Feb), 36-40.

Chesbrough, H., Vanhaverbeke, W., \& West, J. (2006). Open innovation: Researching a new paradigm. New York: Oxford University Press. 
Davidow, W. H., \& Malone, M. S. (1992). The virtual corporation: Structuring and revitalizing the corporation for the 21st century. New York: HarperCollins Publishers.

Duarte, D. L., \& Snyder, N. T. (2006). Mastering virtual teams: Strategies, tools, and techniques that succeed (3rd ed.). San Francisco, CA: Jossey-Bass.

Etzkowitz, H. (2008). The triple belix: University-industry-government innovation in action. New York, NY: Routledge.

Gassmann, O., \& von Zedtwitz, M. (2003). Trends and determinants of managing virtual R\&D teams. R\&D Management, 33(3), 243-262.

Gassmann, O. (2006). Opening up the innovation process: towards an agenda. R \& D Management, 36(3), 223-228.

Hagedoorn, J., Link, A. N., \& Vonortas, N. S. (2000). Research partnerships. Research Policy, 29(4-5): 567586.

Hanebuth, A. (2015, forthcoming). Managing R\&D collaboration as virtual organization - A suitable concept? Journal of Business and Economics, 6(4).

Johnson, P., Heimann, V., \& O’Neill, K. (2001). The “wonderland” of virtual teams. Journal of Workplace Learning, 13(1), 24-30.

Hertel, G., Geister, S., \& Konradt, U. (2005). Managing virtual teams: A review of current empirical research. Human Resource Management Review, 15(1), 69-95.

Kasper-Fuehrer, E. C., \& Ashkanasy, N. M. (2003). The interorganizational virtual organizations. International Studies of Management and Organization, 33(4): 34-64.

Kayworth, T. R., \& Leidner, D. E. (2002). Leadership effectiveness in global virtual teams. Journal of Management Information Systems, 18(3), 7-40.

Kayworth, T. R., \& Leidner, D. E. (2000). The global virtual manager: A prescription for success. European Management Journal, 18(2), 183-194.

Kirkman, B. L., Rosen, B., Gibson, C. B., Tesluk, P. E., \& McPherson, S. O. (2002). Five challenges to virtual team success: Lessons from Sabre, Inc. Academy of Management Executive, 16(3), 67-79.

Kratzer, J., Leenders, R. T. A. J., \& van Engelen, J. M. L. (2006). Managing creative team performance in virtual environments: an empirical study in 44 R\&D teams. Technovation, 26(1): 42-49.

Kraut, R., Egido, C., \& Galegher, J. (1988). Patterns of contact and communication in scientific research collaboration. In Proceedings of the 1988 ACM conference on Computer-supported cooperative work (pp.1-12). Portland, Oregon, United States: ACM.

Lipnack, J., \& Stamps. J. (1997). Virtual teams: Reaching across space, Time and organizations with technology. New York: John Wiley.

Lurey, J. S., \& Raisinghani, M. S. (2001). An empirical study of best practices in virtual teams. Information \& Management, 38(8), 523-544.

Picot, A., Reichwald, R., \& Wigand, R. T. (2003). Die grenzenlose Unternehmung: Information, Organisation und Management. Lebrbuch zur Unternehmensfiubrung im Informationszeitalter (5th ed.). Wiesbaden: Betriebswirtschaftlicher Verl. Gabler.

Powell, A., Piccoli, G., \& Ives, B. (2004a). Virtual teams. ACM SIGMIS Database, 35(1), 6-36.

Powell, A., Piccoli, G., \& Ives, B. (2004b). Virtual teams: A review of current literature and directions for future research. Data Base for Advances in Information Systems, 35(1), 6-23.

Snow, C. C., Miles, R. E., \& Coleman, H. J., JR. (1992). Managing 21st century network organizations. Organizational Dynamics, 20(3), 5-20.

Weisenfeld, U., Fisscher, O., Pearson, A., \& Brockhoff, K. (2001). Managing technology as a virtual enterprise. R\&D Management, 31(3), 323-334.

Zakaria, N., Amelinckx, A., \& Wilemon, D. (2004). Working together apart? Building a knowledge-sharing culture for global virtual teams. Creativity and innovation management, 13(1), 15-29. 


\section{Appendix}

Table 3: Results of success factor aspects (answer range: $4=$ totally agree, $3=$ rather agree, $2=$ rather disagree, $1=$ totally disagree)

National group $(\mathrm{n}=6)$

Regional group $(\mathrm{n}=9)$

Scores

(SD)

Scores

(SD)

Local group $(\mathrm{n}=3)$

Scores

(SD)

ICT

\begin{tabular}{|c|c|c|c|c|c|c|}
\hline $\begin{array}{l}\text { There are communication standards } \\
\text { used by everybody. }\end{array}$ & 3,167 & 1,213 & 3,333 & 1,054 & 3,333 & 0,471 \\
\hline $\begin{array}{l}\text { I'm equipped with all the necessary } \\
\text { ICT. }\end{array}$ & 3,833 & 0,373 & 4,000 & 0,000 & 4,000 & 0,000 \\
\hline I have access to ICT. & 3,833 & 0,373 & 3,778 & 0,416 & 3,333 & 0,471 \\
\hline I'm skilled in using ICT. & 4,000 & 0,000 & 2,778 & 1,030 & 2,667 & 0,471 \\
\hline \multicolumn{7}{|l|}{ Processes and standards } \\
\hline $\begin{array}{l}\text { There are explicit project standards } \\
\text { used by all partners. }\end{array}$ & 3,500 & 1,118 & 3,889 & 0,314 & 3,333 & 0,943 \\
\hline I make use those standards. & 3,500 & 1,118 & 3,778 & 0,629 & 3,333 & 0,943 \\
\hline $\begin{array}{l}\text { There are implicit (informal) stand- } \\
\text { ards used by all partners. }\end{array}$ & 2,667 & 1,374 & 3,111 & 1,197 & 3,667 & 0,471 \\
\hline $\begin{array}{l}\text { Our team adapts the processes if } \\
\text { necessary. }\end{array}$ & 4,000 & 0,000 & 4,000 & 0,000 & 4,000 & 0,000 \\
\hline $\begin{array}{l}\text { My work environment (colleagues, } \\
\text { institutes) supports the cooperation. }\end{array}$ & 4,000 & 0,000 & 3,556 & 0,685 & 4,000 & 0,000 \\
\hline $\begin{array}{l}\text { I rely on colleagues in order to fulfill } \\
\text { my task. }\end{array}$ & 2,833 & 1,344 & 3,556 & 0,956 & 3,667 & 0,471 \\
\hline $\begin{array}{l}\text { I have access to all the information I } \\
\text { need. }\end{array}$ & 4,000 & 0,000 & 3,222 & 1,030 & 4,000 & 0,000 \\
\hline \multicolumn{7}{|l|}{ Organizational Culture } \\
\hline $\begin{array}{l}\text { The organizational culture in my } \\
\text { close team is very trustful. }\end{array}$ & 4,000 & 0,000 & 3,778 & 0,416 & 4,000 & 0,000 \\
\hline $\begin{array}{l}\text { The relation between my team and } \\
\text { the whole project team is very trust- } \\
\text { ful. }\end{array}$ & 3,167 & 0,687 & 3,333 & 0,667 & 2,667 & 0,471 \\
\hline $\begin{array}{l}\text { I appreciate people from different } \\
\text { cultures. }\end{array}$ & 4,000 & 0,000 & 4,000 & 0,000 & 4,000 & 0,000 \\
\hline $\begin{array}{l}\text { I meet my colleagues outside busi- } \\
\text { ness hours. }\end{array}$ & 3,333 & 0,943 & 3,333 & 1,054 & 4,000 & 0,000 \\
\hline $\begin{array}{l}\text { Within our team we support each } \\
\text { other and ask for advice. }\end{array}$ & 4,000 & 0,000 & 3,778 & 0,416 & 4,000 & 0,000 \\
\hline I feel belonging to the overall project. & 3,667 & 0,471 & 4,000 & 0,000 & 4,000 & 0,000 \\
\hline I feel belonging to my institute/chair. & 4,000 & 0,000 & 3,778 & 0,629 & 3,667 & 0,471 \\
\hline $\begin{array}{l}\text { I feel belonging to my organiza- } \\
\text { tion/institute. }\end{array}$ & 4,000 & 0,000 & 3,889 & 0,314 & 3,667 & 0,471 \\
\hline $\begin{array}{l}\text { The other team members appreciate } \\
\text { my work from my point of view. }\end{array}$ & 4,000 & 0,000 & 3,444 & 0,831 & 3,667 & 0,471 \\
\hline \multicolumn{7}{|l|}{ Human resource management } \\
\hline $\begin{array}{l}\text { There is a reward system for working } \\
\text { over geographic distances. }\end{array}$ & 1,000 & 0,000 & 1,222 & 0,416 & 1,667 & 0,471 \\
\hline $\begin{array}{l}\text { It is the research success I'm re- } \\
\text { warded for. }\end{array}$ & 4,000 & 0,000 & 2,500 & 0,866 & 3,667 & 0,471 \\
\hline $\begin{array}{l}\text { It is the project success I'm rewarded } \\
\text { for. }\end{array}$ & 3,000 & 0,894 & 2,889 & 0,994 & 3,667 & 0,471 \\
\hline $\begin{array}{l}\text { Unconventional work arrangements } \\
\text { are supported from the project lead- }\end{array}$ & 4,000 & 0,000 & 2,286 & 1,278 & 4,000 & 0,000 \\
\hline
\end{tabular}




\begin{tabular}{|c|c|c|c|c|c|c|}
\hline \multirow{3}{*}{ ership. } & \multicolumn{2}{|c|}{ National group $(n=6)$} & \multicolumn{2}{|c|}{ Regional group $(n=9)$} & \multicolumn{2}{|c|}{ Local group $(n=3)$} \\
\hline & Scores & (SD) & Scores & (SD) & Scores & (SD) \\
\hline & & & & & & \\
\hline \multirow{2}{*}{$\begin{array}{l}\text { l'm not shy at being proactive. } \\
\text { I'm not shy at participating in im- } \\
\text { portant decisions. }\end{array}$} & 4,000 & 0,000 & 4,000 & 0,000 & 4,000 & 0,000 \\
\hline & 3,833 & 0,373 & 4,000 & 0,000 & 4,000 & 0,000 \\
\hline \multicolumn{7}{|l|}{ On the job development } \\
\hline $\begin{array}{l}\text { There is access to interesting train- } \\
\text { ing provided within the project. }\end{array}$ & 1,000 & 0,000 & 1,333 & 0,943 & 2,000 & 1,414 \\
\hline $\begin{array}{l}\text { My employer offers me access to } \\
\text { training for working across cultures. }\end{array}$ & 3,667 & 0,471 & 3,556 & 0,685 & 2,333 & 0,943 \\
\hline $\begin{array}{l}\text { My employer offers me access to } \\
\text { training for working across geo- } \\
\text { graphic distances. }\end{array}$ & 2,333 & 1,106 & 3,556 & 0,956 & 1,000 & 0,000 \\
\hline \multicolumn{7}{|l|}{ Leadership } \\
\hline $\begin{array}{l}\text { The project coordinator help gain the } \\
\text { support of other stakeholders and } \\
\text { partners. }\end{array}$ & 3,833 & 0,373 & 3,778 & 0,416 & 2,667 & 0,943 \\
\hline $\begin{array}{l}\text { The project coordinator supports and } \\
\text { develops working across organiza- } \\
\text { tional boundaries. }\end{array}$ & 3,833 & 0,373 & 3,556 & 0,685 & 2,000 & 0,816 \\
\hline $\begin{array}{l}\text { The project coordinator supports and } \\
\text { develops the efficient use of new } \\
\text { communication technologies. }\end{array}$ & 3,833 & 0,373 & 3,500 & 0,707 & 1,333 & 0,471 \\
\hline The project coordinator is open. & 4,000 & 0,000 & 3,889 & 0,314 & 3,000 & 0,816 \\
\hline $\begin{array}{l}\text { The project coordinator is easy to } \\
\text { approach. }\end{array}$ & 4,000 & 0,000 & 3,889 & 0,314 & 3,667 & 0,471 \\
\hline $\begin{array}{l}\text { The project coordinator is helpful/ } \\
\text { cooperative. }\end{array}$ & 4,000 & 0,000 & 4,000 & 0,000 & 3,333 & 0,943 \\
\hline The project coordinator is supportive. & 4,000 & 0,000 & 4,000 & 0,000 & 3,000 & 0,816 \\
\hline $\begin{array}{l}\text { The project coordinator is familiar } \\
\text { with the communication technolo- } \\
\text { gies. }\end{array}$ & 4,000 & 0,000 & 4,000 & 0,000 & 3,333 & 0,471 \\
\hline $\begin{array}{l}\text { The project coordinator acts as a } \\
\text { role model in using these communi- } \\
\text { cation technologies. }\end{array}$ & 4,000 & 0,000 & 3,444 & 0,956 & 2,000 & 0,816 \\
\hline \multicolumn{7}{|c|}{ Experience in working in the virtual environment } \\
\hline $\begin{array}{l}\text { I think the project coordinator is ex- } \\
\text { perienced in working in the virtual } \\
\text { environment. }\end{array}$ & 3,600 & 0,490 & 3,500 & 0,866 & 2,333 & 1,247 \\
\hline $\begin{array}{l}\text { I think the project coordinator is ex- } \\
\text { perienced in working across organi- } \\
\text { zational boundaries. }\end{array}$ & 3,600 & 0,800 & 4,000 & 0,000 & 2,667 & 0,943 \\
\hline $\begin{array}{l}\text { I think the project coordinator is ex- } \\
\text { perienced in working across geo- } \\
\text { graphic distances. }\end{array}$ & 4,000 & 0,000 & 3,750 & 0,661 & 2,333 & 1,247 \\
\hline $\begin{array}{l}\text { I am experienced in working in the } \\
\text { virtual environment. }\end{array}$ & 4,000 & 0,000 & 3,667 & 0,667 & 3,667 & 0,471 \\
\hline $\begin{array}{l}\text { I am experienced in working across } \\
\text { organizational boundaries. }\end{array}$ & 3,400 & 0,800 & 3,000 & 1,247 & 4,000 & 0,000 \\
\hline $\begin{array}{l}\text { I am experienced in working across } \\
\text { geographic distances. }\end{array}$ & 3,600 & 0,490 & 3,222 & 1,030 & 4,000 & 0,000 \\
\hline Enjoy being part of the team & 4,000 & 0,000 & 4,000 & 0,000 & 4,000 & 0,000 \\
\hline
\end{tabular}

